University of Wollongong

Research Online

Faculty of Education - Papers (Archive)

Faculty of Arts, Social Sciences \& Humanities

$1-1-2008$

\title{
Healing the Hand that Feeds you: Exploring Solutions for Dog and Community Health and Welfare in Australian Indigenous Cultures
}

Sophie E. Constable

University of Sydney

Graeme Brown

University of Sydney

Roselyn M. Dixon

University of Wollongong, roselyn@uow.edu.au

Robert Dixon

University of Sydney

Follow this and additional works at: https://ro.uow.edu.au/edupapers

Part of the Education Commons

\section{Recommended Citation}

Constable, Sophie E.; Brown, Graeme; Dixon, Roselyn M.; and Dixon, Robert: Healing the Hand that Feeds you: Exploring Solutions for Dog and Community Health and Welfare in Australian Indigenous Cultures 2008, 219-229.

https://ro.uow.edu.au/edupapers/230

Research Online is the open access institutional repository for the University of Wollongong. For further information contact the UOW Library: research-pubs@uow.edu.au 


\title{
Healing the Hand that Feeds You: Exploring Solutions for Dog and Community Health and Welfare in Australian Indigenous Cultures
}

\author{
Sophie Constable, University of Sydney, New South Wales, Australia \\ Graeme Brown, University of Sydney, New South Wales, Australia \\ Roselyn May Dixon, University of Wollongong, New South Wales, Australia \\ Robert John Dixon, University of Sydney, New South Wales, Australia
}

\begin{abstract}
The overpopulation and poor state of dog health in many rural and remote Australian Indigenous communities (RRAIC) affects not only animal welfare but human social welfare. Dogs are an integral part of Australian Indigenous cultures and impact on human health and welfare through zoonotic diseases, and mental health concerns such as worry and shame about pet health, and sleep deprivation from incessant dog fights. This study investigates the factors that contribute to poor animal and community health and welfare in RRAIC, focusing on four main factors: community awareness of dog health and welfare issues, knowledge of the solutions, motivation to access the solutions, and the accessibility of the solutions. Semi structured interviews with local indigenous and non-indigenous residents in four RRAIC were conducted to explore these factors. This qualitative data was then linked to quantitative dog health and welfare data to compare community and scientific perspectives. The following results were observed: - Knowledge of animal health and welfare issues was high, but restricted to the issues that are empirically evident. There was some to little knowledge of less apparent zoonotic risks. - Knowledge of the solutions was variable depending on the veterinary history of the community. - Motivation to improve dog health and welfare was uniformly high. - Accessibility to the solutions was poor when taking into account the remoteness of the communities, cross-cultural differences, the cost of veterinary services and its low priority in health and governance circles, the frequency and duration of vet visits, and the residents' mobile lifestyle. Improving animal welfare in RRAIC requires a multifaceted approach involving raising more comprehensive public awareness of the major issues and their possible solutions though appropriate community education, as well as improving accessibility of veterinary services at the local level.
\end{abstract}

Keywords: Cultural Studies, Education and Social Welfare, Community Health, Indigenous Health, Animal Health, Developing Communities

\section{Introduction}

I N CONTRAST TO the dominant Euro-Australian tradition, Indigenous Australian societies had a different cultural tradition of living with their canines. Traditional beliefs about canine companions included important roles as spiritual and physical protectors, and companionship (Howe 1993, Parker 2006). They had dingoes as their canine companions rather than domestic dogs, and lived in small mobile family groups less exposed to the infectious disease risk posed by permanent settlements. Dingoes differ from domestic dogs in a number of important ways, such as being able to hunt self-sustainably and being much less prolific breeders (Corbett 2001, Boitani et al. 1995).

In contrast, Indigenous Australians have now lived in permanent townships for 50-200 years and domestic dogs or dog-dingo hybrids have become their canine companions. These dogs are prolific breeders capable of replacing $70 \%$ of their numbers every year (Matter and Daniels, 2000). They are also much more dependant on human carers for essentials like food and water.

This basic pattern of change influencing the present day dog health situation is affected by diverse ecological environments, differing pre-contact cultures, customs, and languages, a range of experiences of colonisation and the levels of isolation from and integration with Euro-Australian culture. However, in many remote Indigenous communities, dog health has been found to be distinctly different to that of owned dogs in urban areas (Jenkins et al 1993, Palmer and Presson 1990, Wilks et al. 1998). In general, rates of infectious disease in these dogs have been found to be higher than those of pet dogs in urban areas, reflecting those found in stray or unwanted dogs in Euro-Australian society. Yet there are many other aspects of the health and welfare of dogs in Indigenous communities that have not been assessed.

Nonetheless, the overpopulation and poor state of dog health in many rural and remote Australian Indigenous communities is such that it affects not only 
animal welfare but also human social welfare. As dogs are an integral part of Australian Indigenous cultures they impact on human health and welfare through zoonotic (transmissible between animal and human) diseases, as well as through mental health concerns such as worry and shame about pet health, and sleep deprivation from barking and dog fights (Shields 1992, Howe 1993).

Factors involved in health problems can be diverse, including individual, societal, and organizational factors. Broader policy and governance factors also interact within a particular physical and economic environment (Nutbeam and Harris 2001). Individual factors such as knowledge of issues and their potential solutions, and motivation to access these, are important pre-requisites for the resolution of health issues. However, the impact of problems of accessing the solution - be they economic, political, cultural, or organizational barriers, should not be neglected. Thus this study explored individual factors as well as broader issues of access to and governance support for dog health in rural and remote Australian Indigenous communities (RRAIC).

This study explores a more complete vision of dog health and welfare in rural and remote communities than has previously been researched. In addition, factors that contribute to the current animal and community health and welfare situation in RRAIC were investigated using qualitative methods. Four main factors were the focus: community awareness of dog health and welfare issues, knowledge of the solutions, motivation to access the solutions, and the accessibility of the solutions. By comparing the data on the actual state of dog health with the qualitative data on people's perspectives on dog health and welfare this study aimed to better understand the current situation in order to develop potential solu- tions to dog health and welfare issues in these communities.

\section{Method}

\section{Communities}

Four Indigenous communities were involved in the study. Community $\mathrm{A}$ and $\mathrm{B}$ were remote desert communities where traditional languages remain strong, and ceremonies are still practised, though housing and services are to a large extent westernised. Community $\mathrm{C}$ was an island community where traditional language is less strong but still important to the community. Community $\mathrm{D}$ was a rural community with a high level of westernisation in terms of housing, clothing and material possessions. However, Aboriginal English is the language preferred by residents.

The communities were chosen to explore differences in culture, housing, and isolation, as part of a larger study.

\section{Participants}

Respondents from all communities were resident adults consenting to be involved in the project, approached opportunistically during an environmental health program (Community D), or a dog health program (communities $\mathrm{A}, \mathrm{B}$, and $\mathrm{C}$ ).

\section{Health Data Collection}

Dog health data was collected using visual assessment of dog health and welfare and by laboratory analysis of samples collected from community dogs, with owner consent.

\section{Visual Assessment}

\begin{tabular}{|l|l|}
\hline Factor Assessed & Definition \\
\hline Number of dogs per house & $\begin{array}{l}\text { The maximum number adult dogs seen at the residence } \\
\text { and confirmed to belong there by the owner(s) }\end{array}$ \\
\hline Access to clean water & $\begin{array}{l}\text { i.e. whether the dogs were actively prevented or unable } \\
\text { to access clean water, exercise, shelter, and the com- } \\
\text { pany of other people and dogs }\end{array}$ \\
\hline Access to exercise & $\begin{array}{l}\text { Assessed on a 1-9 scale where } 5 \text { is ideal, } 9 \text { is grossly } \\
\text { obese and } 1 \text { is emaciated }\end{array}$ \\
\hline Access to human companionship & Presence and degree of severity of fresh wounds \\
\hline Access to canine companionship & $\begin{array}{l}\text { Presence of visible skin disease such as mange-like } \\
\text { Condition Score }\end{array}$ \\
\hline Wounds & \\
\hline Dermatopathy & \\
\hline
\end{tabular}




\section{Laboratory Analysis}

Faecal samples were collected for laboratory detection of Giardia and Salmonella species, via Idexx SNAP kit and culture. Venous blood samples were taken for detection of Heartworm (Dirofilaria immitis) and rickettsial organisms (eg Anaplasma sp.) by the Idexx SNAP 4Dx Test.

\section{Instruments}

Semi-structured interviews were conducted with local residents in the four RRAIC to explore people's attitudes to dogs and the factors they saw as affecting dog and community health.

The participants were informed of the areas in which the researcher was interested in exploring using the following wording:

We are interested in how people feel about dogs here. We'd like to know what are people worried about/concerned about to do with dogs here, what they would like to change about dogs here, and what is important that should not change

The participant was then given extended time to inform the researcher in their own words regarding these issues. Further discussion then followed in order to clarify the information sought. Responses were recorded by the interviewer in writing.

\section{Data Analysis}

Theme analysis was conducted on the qualitative data produced by the interviews. This was then checked by another researcher. The qualitative interview data was then linked to quantitative dog health and welfare data to compare community and scientific perspectives.

\section{Results}

Health and Welfare Assessment

a) Socio-Environmental Health and Welfare

\begin{tabular}{|l|l|l|l|l|l|}
\hline Community & $\begin{array}{l}\text { Number of Dogs } \\
\text { Examined }\end{array}$ & $\begin{array}{l}\text { Number of } \\
\text { Houses } \\
\text { Visited }\end{array}$ & $\begin{array}{l}\text { Pet-Owning } \\
\text { Houses }\end{array}$ & \multicolumn{2}{|l|}{ Dogs per Dog-Owning House* } \\
\cline { 5 - 6 } & 87 & 15 & $93.3 \%$ & 5.8 & range \\
\hline $\mathrm{A}$ & 34 & 7 & $85.7 \%$ & 4.75 & $(2-9)$ \\
\hline $\mathrm{C}$ & 42 & 3 & $\mathrm{NA}^{2}$ & $\mathrm{NA}^{2}$ & $(1-9)$ \\
\hline $\mathrm{D}$ & 26 & 25 & $52 \%$ & 2.15 & $(1-4)$ \\
\hline $\begin{array}{l}\text { * excluding litters } \\
\text { 1 Results compiled from unpublished data and from Brown } 2007\end{array}$ & & \\
\hline
\end{tabular}

\begin{tabular}{|l|l|l|l|l|l|l|}
\hline \multirow{2}{*}{ Community } & \multicolumn{2}{|l|}{ Water Source } & Exercise & Shelter & \multicolumn{2}{l|}{ Companionship } \\
\cline { 2 - 7 } & container & environmental & Canine & Human & & \\
\hline A & $22 \%$ & $78 \%$ & $100 \%$ & $100 \%$ & $100 \%$ & $100 \%$ \\
\hline B & $59 \%$ & $41 \%$ & $100 \%$ & $100 \%$ & $100 \%$ & $100 \%$ \\
\hline C & $2 / 3$ & $1 / 3$ & $100 \%$ & $100 \%$ & $100 \%$ & $100 \%$ \\
\hline D & $74 \%$ & $26 \%$ & $92.6 \%$ & $85 \%$ & $77.7 \%$ & $81.5 \%$ \\
\hline
\end{tabular}

In the rural community (Community D) most dogs $(26 / 27$ or $96 \%)$ had ready access to water. All dogs in the remote Communities $\mathrm{A}, \mathrm{B}$, and $\mathrm{C}$ had access to water. However, there were distinct differences in the source of the water. Many dogs in Communities $A$ and $B$ (78\% and $41 \%$ respectively) were only able to access ground water, which can be a conduit of disease.

All animals had access to shelter from rain, however only 2 dogs had actual kennels, both in the rural community (Community D). In the rural community, most $(23 / 27$ or $85 \%)$ had access to adequate shelter, i.e. 3 walls, a roof, and a raised floor. Many dogs had access to verandahs or house interiors, which was the norm in remote communities (communities $A, B$, and C), where kennels were rare.

All dogs were housed in or had constant access to adequate space $\left(>4.5 \mathrm{~m}^{2}\right)$. In Community $\mathrm{D}$, most $(81.5 \%)$ could exercise freely, $18.5 \%$ were chained, and 3 of these 5 chained dogs were walked regularly. 
Thus $92.6 \%$ got appropriate exercise. In the remote communities, all but 2 dogs were free roaming and so had access to adequate exercise.

In Community $D$, only $4 / 27$ or $15 \%$ of dogs lived in a contained or enclosed area, the majority (85\%) did not have secure fencing. In the remote communities only 2 dogs lived in a contained or enclosed area.
All had access to environmental enrichment such as objects to chew. In terms of enrichment from companionship, in Community $\mathrm{D}$, over three quarters $(21 / 27$ or $77.7 \%)$ had constant canine companionship, and a similar proportion ( $22 / 27$ or $81.5 \%)$ had access to regular human companionship. In the remote communities (Community $\mathrm{A}, \mathrm{B}$, and $\mathrm{C}$ ), all dogs had access to canine and human companionship.

b) Physical Health and Welfare

\begin{tabular}{|l|l|l|l|l|l|l|}
\hline Community & \multicolumn{3}{l|}{ Condition Score } & \multicolumn{2}{l|}{ Wounds } & \multicolumn{2}{l|}{ Dermatopathy } \\
\hline & av. & range & absent & minor & absent & present \\
\hline A & NA & NA & NA & $80.1 \%$ & $19.9 \%$ \\
\hline B & 3.6 & $2-5$ & $88 \%$ & $12 \%$ & $63 \%$ & $37 \%$ \\
\hline C & 4.5 & $2-6.5$ & $77.5 \%$ & $22.5 \%$ & $83 \%$ & $17 \%$ \\
\hline D & 4.8 & $3-7$ & $88.5 \%$ & $11.5 \%$ & 73.1 & $26.9 \%$ \\
\hline
\end{tabular}

At 4.8 , the average condition score in the rural community (D) was almost the ideal condition score of 5 . In the remote communities, the average condition score ranged from 4.5 (mildly underweight) in community $\mathrm{C}$ to 3.6 (poor) in community $\mathrm{B}$.

In the rural community (Community D) there were no animals seen with serious or chronic dermatopathy such as 'leatherbacks', dogs with no hair and chronic skin thickening or discolouration. Over a quarter of dogs ( $7 / 26$ or $26.9 \%$ ) showed signs of mild dermato- pathy such as itchiness or presence of fleas or ticks in the rural community. In contrast, in the remote communities (Communities A, B, and C), there was a range with $17-37 \%$ of dogs being affected with mange-like skin signs, and with more dogs (9.5-12\%) being moderately to markedly affected.

Wounding was present to a minor degree in both rural and remote communities. This ranged from $11.5-22 \%$, which were all small $(<2 \mathrm{~cm}$ in length), and most likely from dog fights.

\section{c) Pathogen Prevalence}

\begin{tabular}{|l|l|l|l|l|}
\hline Community & Giardia & Salmonella & Heartworm & Anaplasma \\
\hline $\mathrm{A}$ & $41.7 \%$ & $36.7 \%$ & $17.6 \%$ & $33.3 \%$ \\
\hline $\mathrm{B}$ & $35.2 \%$ & $38 \%$ & $7.7 \%$ & $25 \%$ \\
\hline $\mathrm{C}$ & $34.6 \%$ & $34.6 \%$ & $0 \%$ & $11.8 \%$ \\
\hline $\mathrm{E}^{3}$ & $20 \%$ & $0 \%$ & $0 \%$ \\
\hline${ }^{3}$ data from nearby similar community & $25 \%$ & & \\
\hline
\end{tabular}

Fecal and blood samples revealed a variable presence of infectious diseases across the four communities. Giardia was an important pathogen in all communities ranging in prevalence from $20-41.7 \%$. Likewise Salmonella was present in $25-38 \%$ of dogs. Heartworm was not found in the rural community or the island community ( $\mathrm{E}$ and $\mathrm{C}$ respectively), and no evidence of Anaplasma was found in the rural community.

\section{Qualitative Data}

\section{Summary of Attitudes to Animals for the Rural Community $D$}

In the rural community (Community D) 21 households consented to participate in the study, and only one household did not consent. 
a) Awareness of the issue

i) Canine health and welfare

Overall residents had a good awareness of the general physical condition of the dogs in the community and the responsibility of owners to look after their dogs. The importance of veterinary procedures such as desexing, worming and vaccination was specifically mentioned by around half $(10 / 21)$ of respondents. Few respondents overtly mentioned the overpopulation of dogs as an issue, though several referred to it indirectly, and one respondent stating that if he could not have his dog desexed, he would have it put down.

Many respondents (12/21) expressed the opinion that owners should look after their pets, attend to their needs and control them, especially in terms of nuisance barking. A number of respondents felt that secure fencing was important to contain pets and exclude strays. Several of the non-pet owners stated that if they had secure fencing they would be interested in getting a pet. As the households surveyed were all renters, many felt that this was the responsibility of the landlord to provide and maintain, though some had themselves attempted to secure an area for their dogs or their property more generally.

\section{ii) Human health and welfare}

In this community dogs barking at night was a serious problem, as roaming dogs interact with those guarding their territory. Barking events occurred regularly throughout every night of the study, and several respondents mentioned their sleep being broken or inhibited by dogs barking. However, half of the respondents $(11 / 21)$ disagreed that dogs should be punished for barking at night, and several respondents associated barking with the guarding function of their dogs. Eight out of $21(38 \%)$ respondents mentioned the guarding function of their dogs as important to them. Further, two respondents noted that according to traditional belief "a dog howling at night is telling you a death is coming".

Six out of 21 participants (28\%) stated they were worried about dog bites or savage dogs. They identified that most dogs were healthy and friendly, though some were not. Several others stated that dogs wouldn't bite if you treated them properly.

Some owners stated feelings of distress and lack of control over the issue of fencing. For example, several owners related how they had felt powerless when witnessing a roaming dog come into their yard and kill their dogs. One felt unwilling to own another dog after this, for fear it should happen again.

Two respondents specifically mentioned that their dogs were part of their "emotional health", and sev- eral others made comments such as 'my pet's part of my family'.

\section{b) Knowledge of the solutions}

All respondents knew there was a veterinarian present in the community. However two respondents stated they believed the desexing operation would kill their pet or make it more aggressive.

Almost no respondents gave solutions to the fencing issue, saying that this was out of their control as they were renters. Only one respondent mentioned that he had taken matters into his own hands and fenced his property at his own expense.

Of those respondents who felt that dogs should be prevented from barking at night, most felt that it was up to individual dog owners to stop their dogs barking by looking after them, making sure they weren't hungry or lonely.

\section{c) Motivation to access the solutions}

This aspect of the data is covered in more detail in Constable, Dixon and Dixon (2008). In summary, though there was variability throughout the community, 16/21 (76\%) respondents made comments that indicated they cared about dogs in the community, with statements such as: 'people love dogs round here', 'there's a lot of dog lovers around here, 'my pet's part of my family', 'dogs are like family', and 'dog is man's best friend'.

\section{d) Accessibility of the solutions}

A veterinarian was present in the community, but several residents cited difficulties in transport to or from the veterinarian, and affordability issues. Others denied problems in either area.

\section{Summary of Attitudes to Animals for Remote Communities $A, B$ and $C$}

In the remote communities $\mathrm{A}, \mathrm{B}$, and $\mathrm{C}, 19,18$, and 18 respondents respectively consented to participate in the study, giving a total of 55 respondents.

\section{a) Awareness of the issue}

In community $\mathrm{A}$, most respondents were aware of the principal dog health problems in the community such as mange (19/19), overpopulation (18/19), cheekiness/aggression (17/19) and environmental health issues. Many respondents remarked on the connection between too many dogs and poor health and quality of life, with two respondents willing to subject their dogs to risky surgery to stop them having puppies, even if it meant they might lose their 
dogs. Nearly all respondents $(17 / 19)$ were aware of the natural guarding tendencies of dogs. Few respondents raised the issues of zoonotic gastrointestinal and blood borne diseases.

In community $\mathrm{B}$, most respondents (13/18) felt there were too many dogs, and many, though fewer, stated specifically that dog health was a concern $(6 / 18)$. Several people $(6 / 18)$ elaborated that there were too many dogs for people to be able to look after them properly, with comments such as:

'I have 5 kids, plus 2 I adopted from my brother, 15 grandkids. How am I supposed to look after dogs too?'

Other concerns included dogs were making people itchy, and that cheeky dogs might hurt people, especially children (8/18).

In community $\mathrm{C}$ there was less agreement on the principal concerns, with a third (6/18) respondents voicing that there were too many dogs, a third $(5 / 18)$ discussing environmental health issues, and only $20 \%$ (4/18) highlighting skin diseases. The most agreement (7/18) was that there were too many dogs to be able to be looked after properly, because of other family responsibilities. A few respondents mentioned dogs interrupting sleep. No respondents raised issues of gastrointestinal or blood borne diseases.

\section{b) Knowledge of the solutions}

In community $A, 6 / 19$ respondents $(32 \%)$ sought advice for solving aggression in the community dogs, but no respondents discussed possible solutions. All respondents knew of the medicine for treating mange, but 3 respondents did not realise that mange was caused by mites. One respondent stated: 'Wendy [not her real name] was the first [person] that cared for dogs, helped dogs get better. Before that they just died', indicating the lack of control people felt over health problems in their dogs.

In Community B there was little awareness of the services a veterinarian could provide, and the community had had only one veterinary visit in living memory.

In Community $\mathrm{C}$ respondents were aware of the regular veterinary services that occurred, and saw the difference it made, but some misconceptions existed about the treatments available. Two respondents also mentioned local treatments such as saltwater as a treatment for dog wounds, and mud as a treatment for dog itchiness.

\section{c) Motivation to access the solutions}

This aspect of the data is covered in more detail in Constable, Dixon and Dixon (2008).

In summary, in community A respondents comments indicated that dogs were considered important in the community and the issues raised were also considered important. This was illustrated by a high uptake of proffered veterinary services by community members.

There was individual variability in feelings towards dogs, with one respondent declaring she hated dogs, but for most respondents there was a strong positive attitude. This was evidenced by many people giving their dogs' skin names ${ }^{1}$, thus including them in the official kin system, and through comments such as:

'Dogs and people, we know each other, even though they only bark, they don't speak, dogs understand us.'

'Dogs have really strong love for people'

'Dogs are like family'

'Dogs guard you when you are asleep, else you might get killed.'

'When a dog dies, people get sick (pointing at her own heart), and when dogs get sick, same.'

At the same time, it was seen that dogs also make life harder, eg biting people, stealing food, making a mess of living areas, barking at night. Some respondents were willing to euthanase some of their dogs by an overdose of anaesthetic, though not by being shot. Two respondents were willing to subject their dogs to surgery to stop them having puppies, even if it meant they might lose their dogs in surgical complications.

Amongst dog owners in community $\mathrm{B}$, there was strong evidence of dogs being important and people caring about them, such as giving them $\operatorname{skin}^{\mathrm{i}}$ names and collars, feeding strays, and in being concerned about their health. Typical comments included 'Dogs are important' and 'Some dogs have skin names'. There was a high uptake of veterinary services when offered. One respondent was strongly of the view that dogs should not be killed because the community would suffer physically. Many others said it was 'ok to kill dogs' so long as it was done properly, not by poisoning or shooting.

In community $\mathrm{C}$ there was evidence of close relationships between people and their dogs, such as giving them country names ${ }^{i}$, expressing worry for them, expressing sadness when they had to leave them, and mourning for them when they died, illustrated by typical comments such as: 'we love dogs'

\footnotetext{
${ }^{1}$ Skin names and Country names are terms indicating relationship in Western Desert and Tiwi kinship systems, respectively. These systems allocate all family members to one of several kinship categories, which then guides relationships between kin.
} 
'they are good mates'. However some dogs did not get enough food, and annoyed other people by scavenging for food on their property, creating a mess, and keeping people awake at night.

\section{d) Accessibility of the solutions}

In community $A$ the low frequency of veterinary visits and their cost were an issue. Due to the remote setting of the community ( 6 hours round trip to the nearest veterinarian), and the lack of private vehicles amongst community members, it was considered difficult to get into town themselves let alone get their dog into town. Intermittent subsidised veterinary visits have occurred in the past. Subsidised veterinary visits recently began but still their future is not guaranteed. There is an increasing call from community members for local training and in-community dog health and management skills.

Community B had had next to no access to veterinary visits in the past, and relied on occasional dog culls by shooting to manage dog numbers and dog health. Subsidised veterinary visits have recently begun but their future is uncertain.

Community $\mathrm{C}$ had regular subsidised veterinary visits but several respondents felt they did not get access to veterinary care when they wanted it, as the veterinarian was too busy when visiting the community. Several respondents approved of the idea of local dog health services.

\section{Discussion}

\section{Health and welfare Data}

\section{a) Socio-environmental health} i) Numbers

The numbers of dogs per dog owning house in this study (2.1- 5.8) were similar to those in a study of Western Australian Indigenous communities (Howe 1993), who found the average ranged from $2.2-3.7$. In her study of Kimberley Indigenous communities, Wilks (1999) found that coastal communities averaged 1.9 dogs per dog owning house, but that further inland, more remote communities averaged up to 5.2. Likewise, in this study the more remote communities had higher numbers of dogs per house than the rural community.

In comparison the Australian average is much lower at 1.2 dogs per dog owning house (Higgins 1984). This higher ratio of dogs to house has been related to higher numbers of humans per house due to housing shortages and resultant overcrowding in Indigenous communities (Howe 1993). When expressed as dogs per person to circumvent the housing issue, Shield (1992), Howe (1993) and Wilks (1999) found that the number of dogs per person in some communities was comparable to the Queensland av- erage, but that in many more remote communities there were still more dogs per person.

\section{ii) Exercise and enrichment}

In studies of urban Australia (Bauman et al 2001, Masters and McGreevy 2008) less than half to $57.2 \%$ of dogs were walked every day to receive adequate exercise. In the remote communities, dogs are free roaming, and do not suffer the same restriction on their exercise as dogs confined to backyards. One respondent identified this fact, noting that kardiya (non-indigenous people) kept their dogs locked up and took them out walking every day, but yapa (Indigenous) dogs were free to run around, and always came back. She implied she believed it was not necessary to keep dogs locked up, and then have to walk them for exercise.

In the rural community, only $14.8 \%$ of dogs were restricted to a secure yard, and required daily walking to ensure they had adequate exercise. Though condition score is multifactorial, with inputs from diet, health, hormonal status and social environment as well as exercise, is it interesting to compare that obesity is rarely a problem in dogs in indigenous communities whereas $41 \%$ of dogs are overweight or obese in non-indigenous communities, where dogs have less access to exercise (McGreevy et al 2005, Masters and McGreevy 2008).

In the rural community, $18.5 \%(5 / 27)$ of dogs were restricted on chains, but only 3 of these 5 dogs were regularly exercised. The 2 chained dogs that were not exercised were older aggressive animals, and were not walked because of their aggression. Behavioural adjustment advice had not been sought as the dogs were considered good guard dogs. This situation, albeit only found in a small number of cases, constitutes a serious welfare issue for the dogs involved.

Walking is important for exercise but also for mental enrichment. Otherwise, dog welfare was generally good in terms of mental enrichment in all communities, with for example objects to chew in abundance and high levels of companionship.

\section{b) Physical health}

Dog physical health data showed dog health to be variable to poor in remote communities. This is congruent with data from other remote Indigenous communities (Jenkins et al. 1993, Palmer and Presson 1990, Wilks 1999, Bradbury and Corlette 2006). Further, in remote communities the average condition score of dogs was consistently below ideal, similar to Bradbury and Corlette (2006)'s data. In comparison only $4.2 \%$ of dogs in urban Australia were in poor or very poor condition (McGreevy et 
al 2005). Reasons given for less than ideal condition scores in dogs in the rural community ( 7 dogs), included lactating females ( 2 dogs) and chasing females on heat (one dog).

Likewise, the high prevalence of skin disease (17$37 \%$ ) is comparable to Bradbury and Corlette's data where $24-77 \%$ of houses in an Indigenous community in the wet tropics of the Northern Territory had dogs with visible signs of mange. In comparison, the highest incidence of mange recorded in wild dingoes is $20 \%$ (Corbett 2001). In urban areas, sarcoptic mange is rare, having been cited as causing $4-7 \%$ of dermatological conditions in dogs (Carlotti 1997), whilst demodectic mange is more prevalent.

The high prevalence of gastrointestinal infections found in this study are comparable to results found in other Indigenous communities (Hopkins 1993, Jenkins et al. 1993, Brown 2007, Meloni et al 1993). In contrast, an average of $9 \%$ of urban owned dogs in Australia were infected with Giardia, compared to refuge shelter dogs of whom on average $30 \%$ were diagnosed as infected by faecal examination (Swan and Thompson 1986, Collins, Pope and Griffin 1987). Overseas urban owned-dogs results have ranged from 3-15\% (Nolan and smith 1995, Kirkpatrick 1988, Burnie 1983, Sykes and Fox 1989). The prevalence of Giardia is likely to be affected by environmental conditions in which the host animals live. Environmental conditions affect pathogen survival and likelihood of transmission. Important factors in gastrointestinal pathogen transmission are water supply and chance of faecal-oral transmission. In this study $26-78 \%$ of dogs were only able to access ground water for their water supply, which can be a conduit of disease, especially when combined with poor garbage facilities, as was often the case. Brown (2007) found $35 \%$ of dog faeces contained evidence of disposable nappies (diapers), which illustrates the high risk of gastrointestinal pathogen transmission between people and dogs.

The quantitative health and welfare data show that, there are many areas where dog health is much poorer than urban averages, such as prevalence of infectious disease. However, dogs in these communities are not worse than urban dogs in some aspects (for example exercise and companionship).

\section{Qualitative Data}

Attitudes within the communities reflected knowledge of this state, with concern over dog health and knowledge of prominent animal health and welfare issues being high. However, when compared to the quantitative dog health data, awareness was found to be restricted to the issues that are empirically evident, such as skin problems. There was some to little knowledge of less apparent zoonotic risks, such as gastrointestinal diseases and blood borne disease (Brown 2007, Brown et al 2006). This identifies areas for further raising of awareness.

Knowledge of the solutions to dog issues was variable depending on the veterinary history of the community. Knowledge of a solution appeared to require first hand interaction with a veterinary presence in the community. For example, in Communities $\mathrm{C}$ and $\mathrm{D}$, where a veterinarian visited or was present (respectively), more breadth of knowledge of veterinary treatments was known, though misconceptions still existed. In comparison, community B that had little to no interaction with a veterinarian had little to no knowledge of possible veterinary treatments.

Motivation to improve dog health and welfare was high in all communities, with $75 \%$ of all respondents finding dogs important for their community. A continuing influence of traditional culture may be a part of this, as evidenced by importance of sharing and caring, and spiritual factors mentioned such as beliefs about dogs howling at night. Support for animal management/dog health-care programs was contingent on them being carried out 'in the right way' e.g. not by shooting or poisoning dogs. Another important issue was 'no time' for dog issues because of other responsibilities such as for family. This particular issue is very broad and requires whole of community progress, nevertheless, improving dog health is an important part of this.

Accessibility of the solutions was poor when taking into account the remoteness of the communities, cross-cuitural differences, the cost of veterinary services and its low priority in higher health and governance circles. Compounding this were the infrequency and short duration of veterinary visits, and the community members' mobile lifestyle. Further, many dog issues required collaboration from extraveterinary fields to be improved. For example, in community $\mathrm{D}$ property fencing was a major matter that cannot be addressed without collaboration with the local Aboriginal housing organisation. Likewise, in communities $\mathrm{A}$ and $\mathrm{B}$, efficient garbage disposal is part of the issue of decreasing the food supply available to stray dogs and reducing the risk of dogs eating babies' nappies.

Accessibility of veterinary services was irregular and insufficient in all remote communities, and could be improved by following the local residents call for local dog health workers, locally trained and employed. Benefits to this would include improved communication and day to day service provision.

Respondents in all communities referred to both the negative and positive effects of dogs in their lives, such as the risk of zoonotic disease and the emotional support that dogs brought them. This highlights the tension intrinsic in dog ownership, supporting the theory of Netting et al. (1987) and 
Dwyer et al (2006) that that the relationship is maintained only when the perceived benefits outweigh or are balanced with the perceived costs. For some people the costs had outweighed the benefits and this was cited as a reason why they no longer owned pet dogs. Others were willing to risk the death of their animals when trying to access a solution to overpopulation, and others actively sought the death of their animals, so heavy had the costs side of the equation become. This was contingent upon the disposal method being humane, reflecting that the owners still cared for the welfare of their dogs.

\section{Conclusion}

As the causes of dog health and welfare issues are multifactorial, so improving animal welfare in RRAIC requires a multifaceted approach. However, this study's data show that considerable community concern exists about dog issues and thus lack of support for solutions is not a limiting factor.

Important limiting factors to improvement of dog health and welfare included awareness of dog health solutions and accessibility of veterinary services. These can be addressed through dog health programs, if run sustainably and appropriately. Thus, major components of Indigenous dog health programs should include increasing more comprehensive public awareness of the pertinent dog and zoonotic health and welfare concerns and their possible solutions, via appropriate community education to address knowledge gaps. Equally important is veterinary or animal management communication with other community services and organisations to devel- op awareness of issues and collaboration on solutions.

Perhaps the most important development that could be made would be to improving the accessibility of veterinary services at the local level by training and employing local residents as dog health workers. These people could provide first aid and simple but effective preventative medicine and treatments, as well as being the best conduits for health education information to the local community.

This study has defined several health and welfare issues of importance for dogs and their owners in RRAIC, as well as areas in which dog welfare is better than urban averages. This study demonstrates that community members do have awareness of and concerns for their dogs and their health and welfare. This knowledge should provide the impetus for continuing knowledge development of community members, capacity building through training of local people in dog health and welfare and improved engagement with dog health programs. This study should also assist in policy development and planning for this group of disadvantaged Australians with ultimate benefits to the people and their dogs.

\section{Acknowledgements}

We would like to thank the participants for their time, insights, and support. This project was funded by an Australian Research Council Linkage Program Grant. The collaboration of Animal Management in Rural and Remote Communities (AMMRIC) and Idexx Australia are gratefully appreciated. Sophie Constable is an Australian Postgraduate Award scholar.

\section{References}

Bauman A.E., Russell S.J., Furber S.E. et al 2001, "The Epidemiology of dog walking: an unmet need for human and canine health" Medical Journal of Australia 175:632-634

Boitani L., Francisci F., et al. (1995). Population biology and ecology of feral dogs in central Italy. The Domestic Dog: its Evolution, Behaviour, and Interactions with People. S. J.A. Cambridge, Cambridge University Press: 217-244.

Bradbury L. and Corlette S. (2006). "Dog Health Program in Numbulwar, a remote Aboriginal community in east Arnhem Land"." Australian Veterinary Journal 84(9): 317-320.

Brown G. 2007 "Dogs Dwellings and Diseases: Investigating links between dog health and human health in a remote Aboriginal community" Proceedings of Dog People Conference 16-21 July 2007AMRRIC, Darwin p109-115

Brown G.K., Canfield P.J., et al. (2006). "Detection of Anaplasma platys and Babesia canis vogeli and their impact on platelet numbers in free-roaming dogs associated with remote Aboriginal communities in Australia." Australian Veterinary Journal 84(9): 321-325.

Burnie A.G., Simpson J.W., et al. (1983). "The excretion of Camplyobacter, Salmonellae and Giardia lamblia in the faeces of stray dogs." Vet Res Comm 6: 133-9.

Carlotti D.N. (1997). Canine Scabies: An Update. 29th World Congress of the World Small Animal Veterinary Association, Rhodes

Collins G. H., Pope S. E., et al. (1987). "Diagnosis and prevalence of Giardia in dogs and cats." Australian Veterinary Journal 64: 89-90.

Constable S.E., Dixon R.M. and Dixon R.J, 2008 "For the Love of Dog: The Human-Dog Bond in rural and remote Australian Indigenous communities." Paper presented at ISAZ Conference, Toronto, Canada, $13^{\text {th }}-15^{\text {th }}$ August

Corbett L. (2001). The Dingo in Australia and Asia. Marleston, JB Books.

Higgins P. 1984 "Pet Ownership in Australia" Australian Veterinary Practitioner 14(2):93 
Hopkins R.M., Deplazes P., Meloni B.P., Reynoldson J. A. and Thompson R. C. A. 1993 "A field and laboratory evaluation of a commercial ELISA for the detection of Giardia coproantigens in humans and dogs." Transactions Of The Royal Society Of Tropical Medicine And Hygiene (1993) 87, 39-41

Howe M.L. (1993). The Bio-sociological relationship between Western Australia Aboriginals and their dogs. $\mathrm{PhD}$ thesis, School of Veterinary Studies. Perth, Murdoch University.

Jenkins D.J., Meek P.D., et al. (1993). "Aboriginal community dogs: worms, control and human health." Dog Health in Indigenous Communities: Proceedings of a Conference held in Darwin 1993 as part of the Western Pacific Veterinary Conference, Darwin.

Kirkpatrick C.E. (1988). "Epizootiology of Endoparasitic Infections in Pet Dogs and Cats Presented to a Veterinary Teaching Hospital." Veterinary Parasitology 30: 113-124.

McGreevy P, Thomson P.C., Pride C, Fawcett A, Grassi T and Jones T 2005 "Prevalence of obesity in dogs examined by Australian veterinary practices and the risk factors involved" The Veterinary Record 156:695-702

Macdonald E. 2006 Population-Health-Environment: Improving hygiene and children's health in remote Australian Indigenous communities $\mathrm{PhD}$ thesis, Charles Darwin University, Darwin

Masters A.M. and McGreevy P.D. 2008 "Dog keeping practices as reported by readers of an Australian Dog enthusiast magazine" Australian Veterinary Journal 86: 18-25

Matter HC and Daniels MJ 2000 "Dog ecology and population biology" in Macpherson CNL, Meslin FX, and Wandeler AI (eds) Dogs, Zoonoses and Public Health CABI Publishing Oxford p 17-62

Meloni B.P., Thompson R.C.A., Hopkins R.M., Reynoldson A.J., and Gracey M. 1993 "The prevalence of Giardia and other intestinal parasites in children dogs and cats from Aboriginal communities in the Kimberley" Medical Journal of Australia 158:157-159

Nolan T.J. and Smith G. (1995). "Time series analysis of the prevalence of endoparasitic infections in cats and dogs presented to a veterinary teaching hospital." Veterinary Parasitology 59: 87-96.

Nutbeam D., Harris E. 2001 Theory in a nutshell: a guide to health promotion theory. North Ryde: McGraw Hill Australia,

Palmer A.B. and Presson B.L. 1990 Aboriginal community canine and parasitic disease and population control coupled with field/lab test programme. Darwin: Northern Territory Department of Aboriginal Affairs 1-224

Parker M.A. (2006). Bringing the Dingo home: Discursive representations of the dingo by Aboriginal, Colonial and Contemporary Australians. Faculty of Arts, University of Tasmania

Shield J. 1992 "Some problems of dog health and control in Aboriginal and Islander Communities in North Queensland" Proceedings of the 1st Annual Conference of Urban Animal Management, Chiron Media, Mackay

Swan J.M. and Thompson R.C.A. (1986). "The prevalence of Giardia in dogs and cats in Perth, Western Australia." Australian Veterinary Journal 63(4): 110-112.

Sykes T.J. and Fox M.T. (1989). "Patterns of infection with Giardia in dogs in London." Transactions of The Royal Society of Tropical Medicine And Hygiene 83: 239-40.

Wilks K and Williamson P 1998 "The dog health program in Aboriginal communities - a method for dog management in remote Aboriginal communities" Proceedings of the 7th Annual Conference of Urban Animal Management, Chiron Media, Mackay

Wilks K. 1999. Canine zoonoses in Aboriginal communities: the effects of a canine breeding program in the Kimberley Region, Western Australia.Thesis, Veterinary Science. WA, Murdoch University

\section{About the Authors}

Dr. Sophie Constable

Dr. Sophie Constable is currently working on dog health education in Australian Indigenous communities for her $\mathrm{PhD}$ as part of the "Healthy Dogs Healthy, Communities Project" through the University of Sydney. She completed a Masters of Educational Studies, focusing on Indigenous Education, at the University of Newcastle in 2006. Sophie is a veterinarian and an education coordinator and presenter for the AVA/RSPCA CAWS (Community Animal Welfare Scheme).

Dr. Graeme Brown

University of Sydney, Australia

Dr. Roselyn May Dixon

Dr. Rose Dixon is a special education lecturer at the University of Wollongong, Australia. She has published in the areas of social competence and people with disabilities. She is also involved with Early childhood intervention for children with special needs. She is part of a large research team that is examining culturally relevant education programs in rural and remote Indigenous communities. Another research interest is the application of Social Comparison Theory and Social Cultural Theeory to children with special needs. Dr. Dixon is the Undergraduate supervisor of Special education and the Deputy Director of the Early Childhood program. 
Dr. Robert John Dixon

University of Sydney, Australia 